\title{
The Trends of IT Convergence in Korea
}

\author{
Sung-Youl Lee*
}

\begin{abstract}
These days, the environment of IT development goes through converging with various industries and technologies. Also, it accelerates to pioneer new markets and develop new technologies. This trend becomes one of the most important factors to explore new national growth engines in Korea.

Thus, this research examines current trends of IT convergence in Korea. The strategic characteristics of IT convergence in overseas are briefly explained for comparing purpose. The governmental strategies or efforts regarding the IT convergence have been surveyed. Some example convergences of LG, Samsung, and POSCO as major IT industries in Korea have been introduced. It also identifies several buzz concepts in this field.

The study aims to provide an insight about the activities that are happening in the field of IT convergence in Korea. Finally, the findings through the research have been summarized.
\end{abstract}

Key Words : Trend, IT Convergence, IT Korea, Smart Technology

\section{Introduction}

For last two decades, IT (Information Technology) emerged as one of the most prosperous industry and showed rapid growth in the global world. With improvement and development in technology, more and more traditional industries have incorporated with IT for their continued growth and further development, and IT has become inseparable part of every industry.

Since the various kinds of IC application from 1970 's, the IT industry has been one of the main factors to influence the world economic growth. IT industry is now becoming a driving locomotive of economy in Korea.

IT is changing the business value chain and business system. IT is considered as a factor in the creation of business values in the future from the viewpoint of business competitiveness, business strategy, and work effectiveness. A report published

* Dept. of Computer Science \& Engineering, College of Engineering, Kwandong University by the OECD tells the IT as an essential factor in the creation of business competitiveness and business achievement, and explains IT as a new motive for business growth.

The 21st century is called convergence era. One of the most activating fields in convergence must be IT industry. Recently in all fields of the industry, heterogeneous technologies have converged with IT resulting in a new paradigm. Therefore, this paper deals with the recent trend of IT convergence in Korea. More specifically, various types of convergence with IT have been introduced. The strategic characteristics of IT convergence in overseas are briefly explained for comparing purpose. In order to introduce what is happening in Korea for that issue, some particular technologies or strategies that have been developed from the major IT industry in Korea such as LG, Samsung, or POSCO have been explained as examples. Also, the Korean governmental strategies and/or efforts regarding IT convergence have been explored. 


\section{Evolution of IT}

In early $21^{\text {st }}$ century, the base of digital convergence has been prepared thanks to the trend of dot-com accompanying huge investments. Since then, IT paradigm has been changed from IT-omnipotence to IT-instinct. That is, IT has been evolved to be a tool for improving the quality of life. In 2000, IT served for basic personal demand In 2005, IT improved to provide enriching services. Now, IT is embedded to things and the user uses the IT without any consciousness to the existence of IT. IT will be 'everyware' in our life.

IT has being changed rather based on changes of user's perception in IT application than radical changes based on user's requirements and technology development.

IT market environment has been significantly changed. According to accelerating the convergence between inter-industry and inter-technology, new industries and technologies have been expanding. In order to significantly improve the efficiency of individual industry, IT became the momentum of growth providing the convergence opportunity among various industries. Due to various propensity to consume and personalization, the life cycle of the technology was reduced. The technology became a lot more complicated because of a reduced technology innovation cycle and networking among individual technology. The world market tends to be reorganized as one global market with the emergence of WTO or FTA as an international treaty.

$$
\begin{aligned}
\text { New IT }= & \mathrm{f}\{\mathrm{IT}, \mathrm{xT}, \text { user, industry }\} ; \\
& \text { convergence age }[\mathrm{Yu}, 2008]
\end{aligned}
$$

In convergence age, as shown above pseudo formula, new IT can be defined as a function of IT, various technologies, user and industry. User's needs have been getting complicated. To incorporate this, IT needs convergence with a user. IT combined with the technology and service in various fields could have all been converged by means of the digital technology. That is, IT can be converged with Non-IT. The border between industry and industry has been weakened. It results in convergence of inter-industry.

\section{Advent of New IT}

\begin{tabular}{|l|l|l|}
\hline Complicated & Expanded & Weakened \\
\hline User's Needs & New & Border \\
& Technology & Between Inter \\
User Conv. & IT-Non IT Conv, Inter-Industry Conv. \\
\hline New IT $=\mathbf{f}\{\mathbf{I T}, \mathbf{x T}$, User, Industry $\}$ \\
\hline
\end{tabular}

Figure 1. Advent of New IT [Yu, 2008]

In order to create the industrial value as well as new business model, basically two types of IT convergence have been implemented such as industry with IT, or industry and industry as IT by a medium.

Various fields of technologies and services with IT converged through digital technology by a medium

The general impacts of the convergence are as follows:

1. client's potential value realization $(\mathrm{H} / \mathrm{W}+$ service/solution); iPhone

2. business competitiveness source (company resource inter-company relationship)

3. industry structure reorganization (independent value chain network type)

4. social convenience augmentation (single service convergence service); communication + finance

The impact of convergence to business can be well shown by example. When the Apple focuses only on PC manufacturing in 2000, the aggregate market value of the Apple was 17 billion dollars 
(3\% of Microsoft). However, when the Apple focused on convergence such as iPad which is combined with iPod, iTunes, and iPhone in 2010, it became around 222 billion dollars which exceeds the Microsoft's (219 billion dollars).

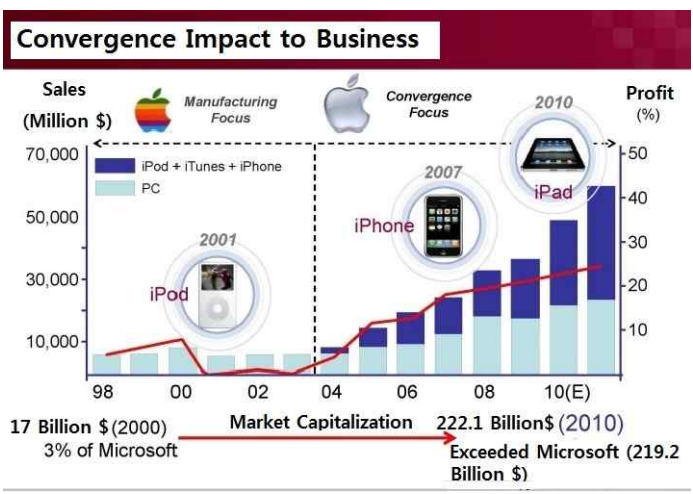

Figure 2. Convergence Impact to Business [Kim, 2010]

Now, the convergence evolutes even to 'Trivergence' as a form of $\mathrm{H} / \mathrm{W}+\mathrm{S} / \mathrm{W}+$ Network to be a new industry paradigm. For instance, Samsung Electronics and LG Electronics both introduced Internet (IP) TV (or smart TV) which has no needs of the set-up box. It enables convenient Internet search as well as plays moving image downloaded.

In the near future, the use of IT is expected to develop in a shape of natural use in daily life, not based on specialties. IT convergence incorporated with other industries is expected to evolve ultimately into the form of the substitutes of human's 5 senses.

\section{Strategic Characteristics of the Overseas IT Convergence}

Since early 2000s, the major countries including Korea have selected IT convergence as their growth engine. Especially, responding to recent importance of the green growth, most countries commonly emphasized the convergence between IT and green technology.

For comparing purpose, the characteristics of IT convergence of the four major countries are briefly explained as follows: [IT Convergence PD, 2010]

\subsection{USA}

The core of the convergence defines a combination of 4 high end technologies such as NT, BT, IT, and CS (Cognition Science). They Focuses on the synergy effect of the convergence. (NBIC, '02)

\section{$3.2 \mathrm{EU}$}

They are pursuing collaborated purpose and providing a technology mutually possible. Besides USA's NBIC, they include Social Science and liberal arts. (CTEKS, '04)

\subsection{JAPAN}

They are pursuing commercialization through the combination between manufacturing technologies and convergence technologies. They have implemented an industrial strategy that concentrates the seven new growth industries such as fuel cell, consumer electronics, robot, contents, health and medical, environmental energy and business support service through the convergence with IT, BT, NT and ET.

\subsection{KOREA}

Through the synergy combination of NT, BT, IT and existing products, industry, academy and culture, they are creating new value for the sake of economy, social spreading and filling the future demand. (M. of Education Science and Technology, '08)

Also, they are enriching traditional industry through IT convergence. (M. of Knowledge Economy, 
'08)

\section{The IT industry in Korea}

\subsection{Governmental Policy}

Since 2004, Ministry of Information and Communication (now Ministry of Knowledge Economy) has pursued the IT831 project. Based on this project, the IT industry share of Korea GDP was estimated to increase $13.3 \%$ in $2006,17.2 \%$ in 2007 and $21.8 \%$ in 2010. In 2007, Korea was ranked, in the world, as the first in the high speed information telecom industry, the first in the digital opportunity index, and the fifth for the preparation of the electronic government. The broadband internet network was utilized by $76 \%$ of Korean household, comparing with $30 \%$ of American household and the Korean spread rate of cell phones was about $75 \%$, comparing with $60 \%$ of Americans'. [Liu, 2007]

IT has performed a role of a moment as well as infrastructure in overall Korean society. IT has been a decisive contribution in economy growth and sustainable development of Korea.

Some of major IT industries and their products are as follows:

Samsung, LG, SK : notebook, digital TV, mobile phones, IC chips, LCD etc.,

Nexon, CJ Internet of Games : Kart rider, Free Style $\cdots$

SK communication, NHN, Daum Communication, Mega Study : internet portal, contents-music animation, e-learning.

In 2010, the Korean government initiated 31 national policy subjects for the development of convergence technology between 5 major industries and IT with various research bodies as the center. The 5 major industries include shipbuilding, automobile, medical service, construction, and national defense.

The ministry of Knowledge Economy decided to invest total 0.15 billion dollars, which is 0.03 billion dollars per year up to 2012 for 5 years for the convergence technology between industry and IT. Ultimately, the government plans to invest and pursue a realization of Renaissances in major industries by converging IT to all industries.

The Figure 3 shows the investment ratio for the ongoing national 50 'Smart' projects in Korea.

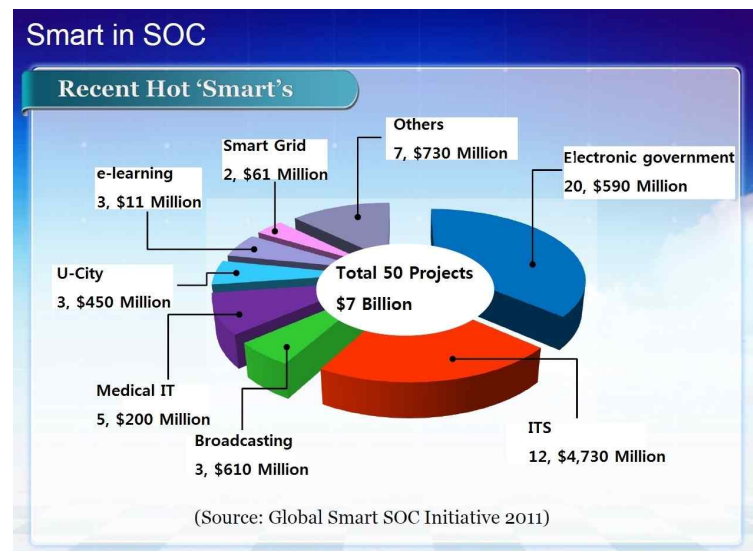

Figure 3. Investments for the 50 Smart projects [Oh, 2011]

Two of major smart projects are summarized as follows:

\section{Smart Transportation}

ITS (Intelligent Transportation System) consists of automobile detect sensor, GPS location tracing mobile communication technology, CCTV, and load condition detector. ITS center gets the information and provides real time traffic control, traffic information connection, integration, processing, and management by means of the internet, cell phone, traffic broad casting and so on. Korea is now ranked the first in the world in the field of ITS. 


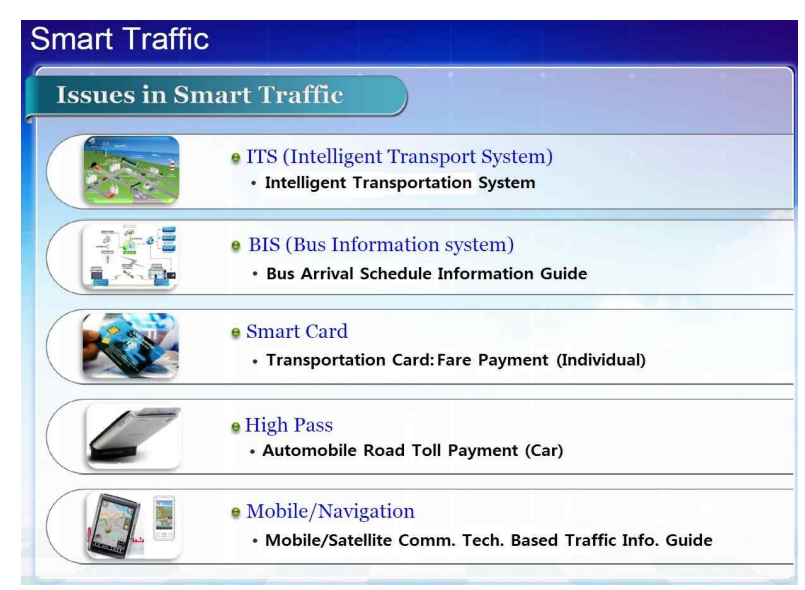

Figure 4. Issues in Smart Traffic [Oh, 2011]

Smart Traffic collects traffic information systematically on risk factors such as traffic flow, accidents, and frozen roads via sensors on roads to synthetically analyze so that it can control traffic lights, IC entry, and reversible lanes for the smoothest flow. As shown in Figure 4, the Smart Traffic project deals with various IT convergence technologies.

It can also deliver such information quickly on traffic via various media such as electronic displays, cell phones, and navigations. Ultimately, it effectively manages congestion and improves road safety. The Korean government initiated a policy titled "One Card, All Pass" from 2009 to 2013 to use one smart card all throughout the country.

\section{Smart Green City}

U-city normally consists of U-education, U-health care, U-facility management, U-traffic control, U-administration, U-security and prevention of disasters, U-media art, and integrated operation center. U-city now extends to smart green city when it includes U-environment and U-energy.

\subsection{Driving Strategy in IT Industry}

The combination of different elements of various technologies created new technologies and products which did not have individual characteristics of the element but new characteristics. New industrial markets have been created using IT. The size of world market share in convergence technology except memory has been 27.7 billion dollars in 2005 up to 92.8 billion dollars in 2010 with an average increasing rate of $27 \%$ yearly.

The convergence between IT and Non-IT has been occurred in a shape of embedded IT and created a good opportunity of new IT service. $\mathrm{Nao}^{-}$ Uki, chairman of Fujitsu said "Automobile and airplane are both a mass of information communication technology (ICT)" in Fujitsu Forum 2008, Tokyo. Recently, Microsoft has cooperated with Ford to make IT automobile. Automobile has been evolved from simple transportation device to digital space.

IT Man'g vs. IT Service World market size - Exceptionally in S/W and IT service Korea IT industry - Concentrated in IT man'g, needs urgent adjustment

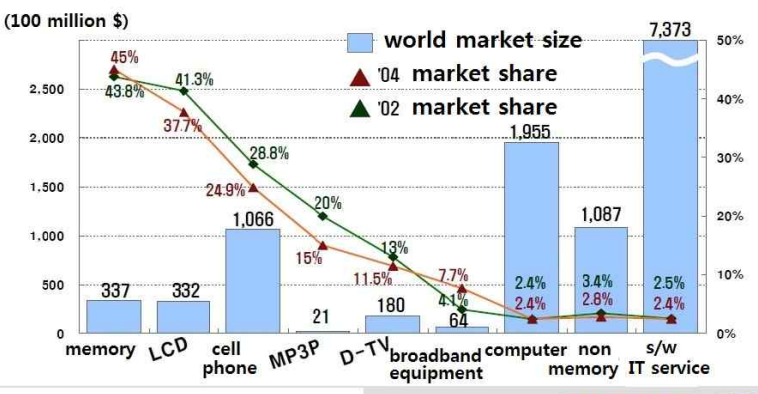

Figure 5. IT manufacturing vs. IT service [Kim, 2005]

IT industry can be basically divided by two area; IT manufacturing and IT service. As shown in Figure 5, IT manufacturing area is saturated and is relatively difficult to generate new added business value. Since Korea is superior to competitiveness in the field of IT, service industry with IT will upgrade the quality and competitiveness of the service. The hardware developed through the convergence of IT industries tends to be standardized and to be easily followed by any other 
businesses. However, the software developed through the convergence of IT service industries is not easy to be followed and is often a source of new business value creation. Therefore, the Korean government should strive to encourage and support the business environment of venture types to develop and excavate the potential IT services. Service science is a right approach to support the industry to be IT conversion and to make IT service a scientific system for the improvement of the productivity and quality.

\subsection{Examples of IT Convergence}

Some example convergences of LG CNS, Samsung SDS, and POSCO ICT as major IT industries in Korea have been introduced.

\subsubsection{LG CNS}

IT convergence strategy in LG CNS is mainly focused on the three areas: mobile, smart, and cloud computing. They are explained briefly as follows:

\section{(1) Mobile}

Through a smart phone and other mobile devices, the company provides various mobile convergence services such as mobile office service, mobile financial service to facilitate corporate communication.

Because of the 3G/Wibro era and mobile traffic congestion, the closure of the communication market occurred. The core of the mobile data is contents. The customer's value criterion changed. Contents and platform became more important factors than network and device. Therefore, prior occupation of OS is getting competitive. Accordingly, application stores were increasingly implemented.

\section{(2) Smart technology}

Various industries could be combined with various smart technologies. Smart car can be implemented when automobile company combines with traffic control and location confirmation. Smart Factory can be implemented as a factory with M2M remote control. Smart Logistics can be implemented as transportation with RFID self-control. Smart space can be implemented as a physical space with virtual space. Smart Grid can be implemented as all electric power users with smart sensing technology in transmission and distribution of electricity.

(3) Cloud computing

According to Wikipedia's definition, cloud computing is a model for enabling ubiquitous, convenient, on-demand network access to a shared pool of configurable computing resources (e.g., networks, servers, storage, applications, and services) that can be rapidly provisioned and released with minimal management effort or service provider interaction.

Computing technology has been dramatically developed since its emergence. When it firstly emerged in '60-'70, mainframe was typical and centralized. Then Client-Server type followed up to ' $900^{-} 00$ with the development of internet and decentralized. Recently web computing era has started and it becomes to extend to cloud computing

\section{Cloud Computing Age 4 . Cloud Computing}

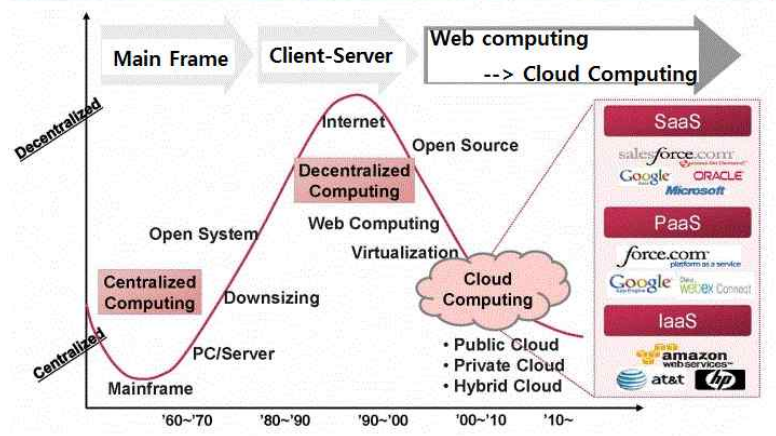

Figure 6. Cloud Computing Age [Kim, 2010]

In cloud computing environment, server based computing with only a tablet $\mathrm{PC}$ or a monitor 
without internet browser, any office software and data provides everything that the user often needs, where as existing high performance notebook needs all of them.

Whenever a customer demands any services or resources from the cloud service portal, the service center which possesses server cloud, storage cloud, backup cloud and desktop cloud provides service to user at anytime, anywhere. Consequently it provides speedy and flexible service. It ultimately saves cost by paying only in proportion to the amount of the resources used.

One of the special IT convergence approaches in the LG CNS is as follows:

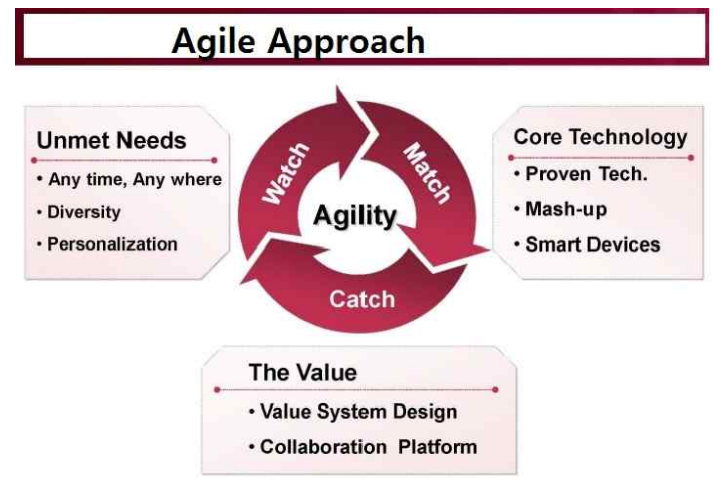

Figure 7. Agile Approach in LG CNS [Kim, 2010]

As shown in Figure 7, the agile approach consists of three stages.

Watch: Find out customer's unmet needs. For examples, the customer may need various services anytime, anywhere, and personally.

Match: To cope with the unmet needs, the customer service should be provided with core technology which may be proven, mash-up and smart devices.

Catch: For the service to be valuable, it needs value system design and collaboration platform.

There is a good example of this kind Amazon-Kindle enables for the user to get many books at once, to read books conveniently, and to purchase books anytime. This is a Watch approach. Second as a Match, it materializes specific device technology such as e-ink, self-display, timing of battery use, and mobile network. Finally as a Catch, it implements eco system with communication, contents and terminal, and converges into inter-industry of mutual value added. AmazonKindle succeeded with the agile approach. However, nobody is sure how long it continues to succeed since other similar developments like iPad has been emerged.

\subsubsection{Samsung SDS}

Samsung SDS tries to create new values by converging customer's products and services with IT. The company materializes the convergence service mainly through the following 4 fields: smart infrastructure engineering, digital space convergence, mobile communication services, and digital hospital/bioinformatics. The individual approach can be summarized as follows: [Samsung SDS homepage, 2011]

(1) Smart infrastructure engineering (SIE)

SIE is a suite of service that improves a customer's operational efficiency and productivity and improves the safety and increases the convenience of services for users by applying intelligent, cutting edge information and communication technologies (ICT) to existing infrastructures. Advancements in cutting edge ICT technologies are bringing changes in our lives, converged with such other industries as transportation and construction. It is leading the transformation into a ubiquitous world by providing such various services as smart city, intelligent transportation system, and intelligent building management system.

(2) Digital space convergence (DSC)

Digital Space Convergence (DSC) implements a futuristic digital convergence space by realizing the 
service required for an emotional space design and user experience into an ICT business. As a cutting edge space based on IT, this service adds more value to smart space and buildings that transcends the traditional limitations of time, space and equipment. DSC space converged with designs that stimulate a user' $\mathrm{s}$ sensibilities brings forward the improvement of a user' s quality of life and a futuristic information society. The company realized this concept to the several domestic university libraries by creating a new value for space through the convergence of IT and construction.

(3) Mobile communication

Mobile communication is a service that provides customers with the solutions and capabilities required for responding to digital convergence in mobility and telecommunications. Due to rapid advancements in ICT, competition among enterprises have expanded into the global market, which has been made possible by real time business environments that enable communication among remote places and pose no limitations in time and space.

It provides mobile groupware, applications, enterprise SNS, a mobile service platform, and an integrated messaging service which has been integrated with mobile devices such as smart phones and tablets.

(4) Digital hospital/bioinformatics

For an efficient operation of hospitals, the company provides HIS (Hospital Information System), which includes a prescription delivery system and a hospital administration system. EMR (Electronic Medical Record) enables qualitative improvement in treatment by digitizing all patient records, and PACC (Picture Archiving and Communication System) that digitizes medial images.

Also, by providing IT based gene analysis service, they intend to make a pivotal contribution to the development of the gene-based custom diagnosis and treatment industry.

\subsubsection{POSCO ICT (Previous POSDATA and POSCON)}

POSCO ICT'S business area is basically divided into 3 fields: engineering services, advanced construction technology, and smart grid technology.

\section{(1) Engineering service}

The company provides comprehensive engineering services in various areas such as railway, energy, and environment, besides construction from design to procurement, construction, operation, and post management, using IT convergence technology that applies new digital technology.

(2) Advanced construction technology

The company provides IT and engineering convergence technology for all fields of the construction industry, including housing, plant, environment, energy and so forth. In particular, it will enhance the value of buildings, using future-oriented technologies such as IBS, digital home, etc.

(3) Smart grid technology

The Smart Grid Project involves the construction of the next-generation power grid, which will serve to optimize energy efficiency by combining IT with the conventional power grid to enable the interactive, real-time-based communication of power information between power supplier and consumers.

It offers customers a total service for efficient energy use, including energy efficiency consulting, facilities solution construction, and energy control center operation.

Additionally, POSCO ICT implemented an electronic Toll Collection System (ETCS, Hipass) which enables the car to drive without stopping as well as Car Loaded Terminal for it. Also, POSCO ICT plans to explore new IT convergence 
approaches such as user's IT conversion, IT life conversion, service science and human convergence technology by the 2020. The expansion of service science will provide a significant contribution to innovation of the tertiary industries and furthermore, to creation of the quartic industries. POSCO ICT strives to develop and realize the various new IT services and business using U-technology.

\section{Conclusions}

In 20th century, IT infrastructure has been implemented through the mainframe and client-server era. In early 21st century, the base of digital convergence has been prepared thanks to the trend of dot-com accompanying huge investments. These days, IT convergence serves as a momentum of the national growth engine in Korea. Therefore, the study examined what is happening in the field of IT convergence in Korea

In conclusion, the recent trends of IT convergence in Korea can be summarized as follows:

[1] For a last decade, the convergence has evolved from the convergence in IT industry to the one in inter-industry. The convergence speed expects to be more accelerated next decade.

[2] Converging the existing technologies with IT creates new business value. Accordingly, the core of success depends on who does first capture and realize the customer's needs.

[3] The IT convergence is being changed into the shape of embedded IT in human's daily life. It will be 'everyware' in human life.

[4] IT manufacturing industry is now almost fully saturated in Korea. Thus, in order to create new business value, service science using IT seeks to be further explored and pursued to revive growth.

[5] In order to develop and excavate the potential
IT services, the Korean government should strive to encourage and support the business environment of venture types.

Although a sufficient amount of information and data were not reviewed, these summaries hopefully provide a better understanding of the strategic role of IT in convergence environments.

\section{References}

[1] IT Convergence PD, KEIT, "IT Convergence R\&D Strategy and Driving Status", The Proceedings of Korean CAD/CAM Society Conference, 2010.

[2] Kim, Dae-Hoon (President of LG CNS), “ Digital Convergence Era, New Value Creation of IT," The Tutorial VOD of 2010 KIIE-KORMS Spring Joint Conference, 2010.

[3] Kim, In (President of Samsung SDS), "The Present Status and Vision of IT Industry in Korea Focused on IT Service Industry," The Tutorial VOD of 2005 KIIE Fall Conference, 2005.

[4] Kim, M.K., Park, J.H., Cho, Y.W., "Current Trends and Industrial Strategies of IT Convergence," Electronic Communication Trends Analysis, Vol. 25, No. 1, ETRI, 2010.

[5] Kim, Shin-Bae (President of SK C\&C), "The Role of IT Service Industry in Convergence Era," The Tutorial VOD of 2009 KIIE Fall Conference, 2009.

[6] Lee, Gak-Boum, "IT Convergence and Future Management," The Proceedings of 2010 KORMS Fall Conference, 2010.

[7] Lee, Kyung-Ho, "Overview of IT Convergence Technology in Shipbuilding Industry", The Proceedings of 2009 Fall KIIE Conference, 2009.

[8] Lee, Sung-Youl, "The Trends of IT Convergence in Korea," The Proceedings of the 
7th East Asia Economy Forum, Irukutsk Russia, 2011.

[9] LG CNS Homepage, http://www.lgcns.com, 2011.

[10] Liu, Shin Il, "IT Cooperation between R.O. Korea and P.R. China," The Proceedings of KSIIS Spring Conference, 2007.

[11] Oh, Suk-Moon, "Smart Traffic: Public Transportation Traffic Analysis and Decision Making Support" , The Special Tutorial VOD of the 2011 KORMS/KIIE Spring Joint Conference, 2011.

[12] POSCO ICT Homepage, http://www.poscoict.co.kr, 2011.

[13] Samsung SDS Homepage, http://www.sds.samsung.co.kr, 2011.

[14] Yu, Byung-Chang, (President of POSDATA), "Emerging New IT and the Role of Service Science," The Proceedings of 2008 KIIE/KORMS Spring Joint Conference, 2008.

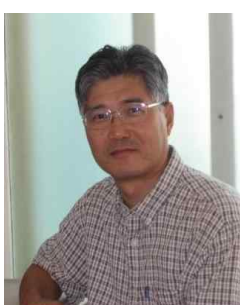

이 성 열 (Sung-Youl Lee)

• 1977 년 인하대학교 기계공학과(학사)

- 1980년 인하대학교 산업공학과(석사)

-1985년 택사스 주립대 산업공학 (석사)

- 1988년 노스다코타 주립대 산업공학(박사)

- 1988-현재 관동대학교 컴퓨터학과 교수

- 관심분야: 컴퓨터 비젼, $\mathrm{HCI}$, 데이터마이닝, 인공신 경망/유전자 알고리듬 응용 